\title{
Causes of death of Thoroughbred racehorses at Octavio Dupont Veterinary Hospital, Brazilian Jockey Club, Rio de Janeiro ${ }^{1}$
}

\author{
Marsel C. Pereira ${ }^{2}$, Guilherme C. Ferraz ${ }^{* 2}$, Antonio S. Ferraudo ${ }^{3}$, Amandio R. Quintelas ${ }^{4}$, \\ Carolina Berkman and Antonio Queiroz-Neto ${ }^{2}$
}

\begin{abstract}
Pereira M.C., Ferraz G.C., Ferraudo A.S., Quintelas A.R., Berkman C. \& Queiroz-Neto A. 2012. Causes of death of Thoroughbred racehorses at Octavio Dupont Veterinary Hospital, Brazilian Jockey Club, Rio de Janeiro. Pesquisa Veterinária Brasileira 32(3):189-193. Laboratório de Fisiologia do Exercício Equino, Departamento de Morfologia e Fisiologia Animal, Faculdade de Ciências Agrárias e Veterinárias, Universidade Estadual Paulista, Jaboticabal, SP 14884-900, Brazil. E-mail: gferraz@fcav.unesp.br

There are few studies that approach the epidemiology of deaths in racehorses in a broad manner. The majority focus on a specific affection or procedure. Brazil does not have a program instituted for the monitoring of deaths of horses. By means of a descriptive study in association with a multivariate analysis method, an epidemiologic profile was determined for deaths related to musculoskeletal (MS), gastrointestinal (GI), respiratory (RES) systems, neurologic origin (NEU) and sudden death (SD) for the years of 2002 to 2008, at the Octavio Dupont Veterinary Hospital-Rio de Janeiro (ODVH). Males comprised the majority of deaths and that deaths were related to, decreasing order, $\mathrm{MS}>\mathrm{GI}>\mathrm{SD}>\mathrm{NEU}>\mathrm{RES}$, with respect to general mortality rate per large group of determined causes (TSPMr). The majority of deaths registered included horses aged four to five years (ID4-ID5). We observed the following correspondence relations: (3-year period = SM - ID >5 - SD; ID>5 - GI; ID4-5 - MS; SF - ID $<4$ - RES/ NEU); (4-year period = SM - ID $>5$ - GI; SF - ID<4 - NEU; ID4-5 - MS; GI - ID >5). The present study points out the importance and necessity of epidemiologic studies of lesions in horses, based on diagnosis for the recognition of predisposing factors and prevention.
\end{abstract}

INDEX TERMS: Horses, race deaths, multivariate correspondence analysis, epidemiology.

RESUMO.- [Causas de mortes de cavalos de corrida registradas no Hospital Veterinário Octávio Dupont, Jockey Clube Brasileiro, Rio de Janeiro.] Existem poucas pesquisas que abordam estudos epidemiológicos de mortes em cavalos de corrida de uma forma ampla. A maioria restringe-se a uma afecção ou procedimento específico. 0 Brasil não possui um programa de monitoramento de mortes instituído. Através de um estudo

\footnotetext{
${ }^{1}$ Received on April 30, 2011.

Accepted for publication on September 14, 2011

${ }^{2}$ Laboratório de Farmacologia e Fisiologia do Exercício Equino (Lafeq), Departamento de Morfologia e Fisiologia Animal, Faculdade de Ciências Agrárias e Veterinárias (FCAV), Universidade Estadual Paulista (Unesp), Campus de Jaboticabal, Via de Acesso Prof. Paulo Donato Castellane s/n, Jaboticabal, SP 14884-900, Brazil. *Corresponding author: gferraz@fcav.unesp.br

${ }^{3}$ Departamento de Ciências Exatas, FCAV-Unesp, Jaboticabal, SP.

${ }^{4}$ Médico Veterinário Autônomo, Rua Teodoro da Silva 659, Sobrado, Vila Isabel, Rio de Janeiro, RJ 20560-000, Brazil.
}

descritivo em associação a metodologia multivariada de análise, realizou-se um estudo epidemiológico de causa mortis relacionadas com afecções musculosqueléticas (MS), gastrointestinais (GI), sistema respiratório (RES), neurológico (NEU) e mortes súbitas (SD) durante os anos de 2002 a 2008 no Hospital Octavio Dupont, Rio de Janeiro. Os machos representaram o sexo mais afetado e a causa mortis relacionada com a taxa geral de mortalidade por grandes grupos de causas determinadas apresentou a seguinte ordem decrescentemente: $\mathrm{MS}>\mathrm{GI}>\mathrm{SD}>\mathrm{NEU}>\mathrm{RES}$. A maioria dos óbitos registrados foi de cavalos na faixa etária de quatro a cinco anos (ID4-ID5). Seguidamente, observaram-se as seguintes relações de correspondência: (Triênio = SM-ID >5-SD; ID>5-GI; ID4-5-MS; SF-ID <4-RES/ NEU); (Quatriênio = SM - ID >5 - GI; SF - ID<4 - NEU; ID4-5 - MS; GI - ID >5). 0 presente estudo aponta a importância e necessidade de estudos epidemiológicos sobre lesões em cavalos atletas, objetivando o diagnostico, reconhecimento de fatores predisponentes e prevenção. 
TERMOS DE INDEXAÇÃO: Equinos, mortes em corridas, análise de correspondência multivariada, epidemiologia.

\section{INTRODUCTION}

There are few studies that examine the epidemiology of deaths in sport horses in a broad manner. The majority focus on a specific affection (Baker \& Johnson 1999) or specific procedure (Johnson et al. 2002). A broader study of causa mortis in a population is of utmost importance in the construction of a diagnostic map and in establishing technical foundation for preventive measures.

In many countries, various entities, equestrian sport associations and research groups in equine medicine, maintain programs for monitoring horse deaths, correlating them with the methodology of breeding and activity performed by the animal, known as "Programs of Postmortem Examination" (Fio 2002, Calkins 2005).

These programs are developed mainly for thoroughbred horses, whose intensive management and routine training and testing expose them to a greater gamut of affections (Fio 2002). There are institutes such as the Centers of Epidemiology and Animal Health of the United States Department of Agriculture (NAHMS 2007), which extend databases beyond musculoskeletal affections, allowing the systemization and inclusion of deaths of all the equine population. Some institutions create epidemiologic scanning programs by means of collecting information from various research groups, converging to a unified database, in order to monitor infectious diseases and clinical affections for the purpose of obtaining a health picture of the equine herd and, subsequently, to foster preventive actions (DEFRA 2008).

Entities, for example, the California Horse Racing Board (CHRB), California Animal Health and Food Safety Laboratory (CAHFS) and University of California (UC Davis), form interdisciplinary research groups with support from the government and breeding associations, based on three principal objectives: 1st- to determine the genesis of the occurrence of the lesions; 2 nd- to determine the reasons for such lesions developing, and 3rd- to develop prevention strategies (Stover and Murray 2008). Research groups such as these, carry out annual necroscopic examinations in more than 2800 horses, producing statistics of extreme importance and gaining not only the respect of the international scientific community, as through preventive measures, but also the return of the public's confidence in the sport (Fio 2002).

There are relatively few works in the national and international literature that interpret epidemiologic surveys in horses utilizing multivariate analysis tools, with even fewer, as in the present study, rerunning the multivariate correspondence analysis of the data. Baker and Johnson (1999) replaced the postmortem evaluation of horses with pneumonia with the annual description of cases and number of bacterial isolates. USDA-UPHIS (2007) and DEFRA/ AHT/BEVA (2008) were restricted to mortality rates and the description of the number of cases per organ system affected, respectively. Calkins (2009), despite determining relations of prevalence between deaths and individual and temporal variables, all were univariate.

The multivariate analysis allows the study of the inter- dependence between the variables of each horse, making it possible to raise specific and accurate questions of considerable complexity, in a set of data, turning m-dimensional information into tri or bi-dimensional (Manly, 2008). Therefore, the aim of this study was to draw an epidemiologic map of the deaths in thoroughbred horses at Hospital Octavio Dupont (JCB/RJ), demonstrating the correspondent relations between the affections found, temporal variables and inherent variables for the succumbed horses.

\section{MATERIALS AND METHODS}

This was a temporal and descriptive study based on data obtained by consulting a databank of deaths at Hospital Octavio Dupont (JCB/RJ), Rio de Janeiro, referring to the years 2002 to 2008. The necropsy reports of 452 Thoroughbred horses were analyzed, separating each study year based on gender (male - SM; female $\mathrm{SF}$ ); age group (less than four years - ID $<4$; between four and five years - ID4-5; more than five years - ID $>5$ ). These age groups were distributed according to the following criteria: ID $<4$ - maximum early Thoroughbred horses on the track; ID4-5- age of major exercise activity; ID> 5- range in which most horses end their careers, but some are still competing. Necropsy reports referring to the categories of affected organ systems (MS-musculoskeletal system, gastrointestinal system - GI, sudden death or unknown cause - SD; respiratory system - RES; neurologic origin - NEU).

The category MS included horses whose necropsy reported showed fracture, luxation, osteoarthritis, laminitis, rabdomyolysis, tendon rupture or cranio-encephalic trauma. The category GI included horses whose necropsy chart showed colic (pre- or postoperative) and diarrhea. The category SD comprised horses whose death was not specifically related to any system analyzed and that occurred suddenly during races or where the cause could not be elucidated. The category RES included horses whose necropsy report showed pleuropneumonia and acute pulmonary edema. The category NEU included horses whose necropsy report indicated equine protozoal myeloencephalitis (EPM) or ataxic syndrome.

Based on the organ systems involved in the causa mortis according to the necropsy report, the determination of proportional mortality rate per major group of determined causes (Total specific proportional mortality rate - TSPMr or Annual specific proportional mortality rate - ASPMr) was calculated using the following formulas:

TSPMr: Sum of deaths by determined cause (x 100) Total deaths recorded

ASPMr: Annual number deaths by determined cause (x 100) Total deaths recorded

Multivariate correspondence analysis ${ }^{5}$ was used with the aim of finding interdependence between categories of affected organ systems (musculoskeletal system - MS; gastrointestinal system GI; sudden death or undetermined cause - SD; respiratory system - RES; neurologic - NEU); gender (male - SM; female - SF) and age (less than four years - ID $<4$; between four and five years - ID4-5; more than five years - ID $>5$ ). During the data compilation has acquired the construction of the individual matrix vs criteria (Burt matrix) in Microsoft Office Excel. Due to the extensive amount of data, tabulation and implementation of these exceeded the columns of the program, creating the need for division into two periods.

Thus, the animals selected were grouped into two temporal ranges: 2002 to 2004 (3-year period) and 2005 to 2008 (4-year

\footnotetext{
${ }^{5}$ STATISTICA 7 (StatSoft) software.
} 
period); with the construction of contingency tables (one for each temporal range) based on the variables to be evaluated (binary matrix of individuals/criteria), crossings between line categories and column categories of the matrix were made, and consecutively, the correspondences between the variables proposed were represented spatially by perceptual maps. The proximities between the constituent variables of the perceptual maps, as well as their arrangement in the maps, demonstrate similarities and dissimilarities between them, representing the intensity of the correspondence relations.

Correspondence analyses were based on the higher chi-squared $\left(\mathrm{X}^{2}\right)$ values transformed into a metric representation of distance. The inertias of each dimension represent the percentage of information retained by them (Hair, 2009). This analysis allows only the exploratory evaluation of relationships between variables through perceptual mapping.

\section{RESULTS}

In the counts for the period of 2002 to 2008, annual totals (Ta) were 81 (2002), 58 (2003), 71 (2004), 72 (2005), 54 (2006), 67 (2007) and 49 (2008) deaths registered and separated into categories according to affection and gender (Table. 1). Males reported a greater number than females, of deaths with regard to the variables MS, GI, SD and RES at all years of evaluation. The number of females was higher only for deaths of neurologic origin (NEU) in five years $(2003,2004,2005,2005$ and 2008). During two years (2002 and 2007) males and females reported an equal number of deaths of neurologic origin. By means of general mortality rate per major group of determined causes (TSPMr), was possible to delineate the following relation in decreasing order: $\mathrm{MS}>\mathrm{GI}>\mathrm{SD}>\mathrm{NEU}>\mathrm{RES}$.

The relation between deaths and categories of organ systems involved are presented in Table 1 . In this manner, of the 452 horses necropsied in the years of 2002 to 2008 at ODVH, the majority, 53\% (241), of deaths were of musculoskeletal (MS) nature. The gastrointestinal system (GI) related causes were responsible for $21 \%$ (96) of the deaths, being the second major cause of the deaths registered. Horses with sudden death (SD) represented 12\% (56) of the deaths. Affections in the respiratory system (RES) were responsible for $6 \%(25)$ of the deaths and $8 \%$ (35) of deaths registered were with affections originating in the neurologic system (NEU).

Correlating the age groups to each year of evaluation, was observed that the majority of deaths registered each year included horses aged four to five years (ID4-5) (2002, $2003,2004,2007$ and 2008). Horses younger than four years old (ID<4) were in the majority only in two $(2005$ and 2006) of the seven years studied. The number of deaths among the horses older than five years (ID $>5$ ) was lower than for the other age groups in all years evaluated.

The perceptual maps (Fig.1 and 2) show the correspondence relations between the variables age (ID $<5$; ID4-5 and ID>5), gender (SM - male; SF - female) and cause of death (MS - musculoskeletal system; GI - gastrointestinal system; SD - sudden death or unknown cause; RES - respiratory system; NEU - neurologic). The first map (Fig.1) refers to the years of 2002 to 2004, and the second (Fig.2) to the years of 2005 to 2008 .
Table 1. Annual numeric and percentage relations of horse deaths and specific and general mortality rates per major group of determined causes occurring in Hospital Veterinário Octavio Dupont (ODVH), 2002 to 2008

\begin{tabular}{|c|c|c|c|c|c|c|c|c|c|}
\hline YEAR & & MS & GI & SD & RES & NEU & Tig & & \\
\hline \multirow{4}{*}{2002} & M & 27 & 13 & 9 & 3 & 3 & 55 & \multirow{4}{*}{ Тa } & \multirow{4}{*}{81} \\
\hline & $\mathrm{F}$ & 13 & 7 & 2 & 1 & 3 & 26 & & \\
\hline & Ticm & 40 & 20 & 11 & 4 & 6 & & & \\
\hline & ASPMr & $8.84 \%$ & $4.42 \%$ & $2.43 \%$ & $0.88 \%$ & $1.32 \%$ & & & \\
\hline \multirow{4}{*}{2003} & M & 17 & 5 & 6 & 3 & 3 & 34 & \multirow{4}{*}{ Ta } & \multirow{4}{*}{58} \\
\hline & $\mathrm{F}$ & 12 & 4 & 2 & 2 & 4 & 24 & & \\
\hline & Ticm & 29 & 9 & 8 & 5 & 7 & & & \\
\hline & ASPMr & $6.41 \%$ & $1.99 \%$ & $1.76 \%$ & $1.10 \%$ & $1.54 \%$ & & & \\
\hline \multirow{3}{*}{2004} & M & 25 & 13 & 11 & 1 & 1 & 51 & \multirow{4}{*}{ Ta } & \multirow{4}{*}{71} \\
\hline & $\mathrm{F}$ & 10 & 3 & 2 & 3 & 3 & 21 & & \\
\hline & Ticm & 35 & 16 & 13 & 4 & 4 & & & \\
\hline \multirow{5}{*}{2005} & ASPMr & $7.74 \%$ & $3.53 \%$ & $2.87 \%$ & $0.88 \%$ & $0.88 \%$ & & & \\
\hline & M & 27 & 10 & 2 & 2 & 0 & 41 & \multirow{4}{*}{ Тa } & \multirow{4}{*}{72} \\
\hline & $\mathrm{F}$ & 17 & 5 & 4 & 2 & 3 & 31 & & \\
\hline & Ticm & 44 & 15 & 6 & 4 & 3 & & & \\
\hline & ASPMr & $9.73 \%$ & $3.31 \%$ & $1.32 \%$ & $0.88 \%$ & $0.66 \%$ & & & \\
\hline \multirow{4}{*}{2006} & M & 15 & 5 & 7 & 1 & 2 & 30 & \multirow{4}{*}{ Тa } & \multirow{4}{*}{54} \\
\hline & $\mathrm{F}$ & 15 & 4 & 2 & 0 & 3 & 24 & & \\
\hline & Ticm & 30 & 9 & 9 & 1 & 5 & & & \\
\hline & ASPMr & $6.63 \%$ & $1.99 \%$ & $1.99 \%$ & $0.22 \%$ & $1.10 \%$ & & & \\
\hline \multirow{3}{*}{2007} & M & 24 & 8 & 3 & 3 & 3 & 41 & \multirow{4}{*}{ Тa } & \multirow{4}{*}{67} \\
\hline & $\mathrm{F}$ & 12 & 6 & 3 & 2 & 3 & 26 & & \\
\hline & Ticm & 36 & 14 & 6 & 5 & 6 & & & \\
\hline \multirow{6}{*}{2008} & ASPMr & $7.96 \%$ & $3.09 \%$ & $1.32 \%$ & $1.10 \%$ & $1.32 \%$ & & & \\
\hline & M & 17 & 10 & 3 & 2 & 1 & 33 & \multirow{4}{*}{ Ta } & \multirow{4}{*}{49} \\
\hline & $\mathrm{F}$ & 10 & 3 & 0 & 0 & 3 & 16 & & \\
\hline & Ticm & 27 & 13 & 3 & 2 & 4 & & & \\
\hline & ASPMr & $5.97 \%$ & $2.87 \%$ & $0.66 \%$ & $0.44 \%$ & $0.88 \%$ & & & \\
\hline & TSPMr & $53 \%$ & $21 \%$ & $12 \%$ & $6 \%$ & $8 \%$ & & & \\
\hline
\end{tabular}

MS = musculoskeletal system; GI = gastrointestinal system; $\mathrm{SD}=$ sudden death or unknown cause; RES = respiratory system; NEU = neurologic; $\mathrm{M}=$ male; $\mathrm{F}$ = female; Ticm = Sum of individuals deaths by cause; Tig = sum of deaths per gender; $\mathrm{Ta}=$ annual total; $\mathrm{Tg}=$ General total sum of all deaths; ASPMr = annual specific proportional mortality rate; TSPMr $=$ total specific proportional mortality rate.

Figure 1 shows a correspondence between males older than five years and deaths resulting from undetermined causes (SD). Females younger than four years, demonstrated correspondences with the variables respiratory (RES) and neurologic (NEU) in the causa mortis).

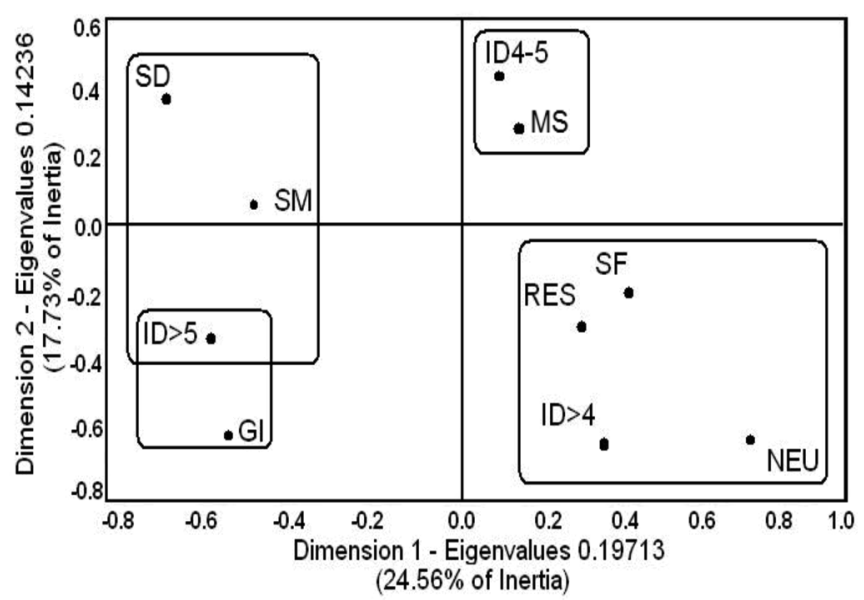

Fig.1. Perceptual map of correspondence relations between the variables gender (SM, SF); age group (ID<4, ID4-5, ID>5) and cause of death (MS, GI, SD, NEU, RES); during the 3-year period 2002, 2003 and 2004. 
Horses older than five years (ID>5) displayed correspondence with gastrointestinal causa mortis (GI), and those belonging to the age group between four and five years (ID4-5), had musculoskeletal (MS) affections origin of the causa mortis.

Figure 2 indicates a correspondence between males older than five years and causa mortis) of gastrointestinal origin. The females with ages less than four years corresponded with deaths of neurologic origin. Horses aged between four and five years (ID4-5) showed, independent of gender, correspondence with deaths of musculoskeletal nature (MS). The deaths of gastrointestinal origin corresponded moderately with horses whose age exceeded five years (ID>5).

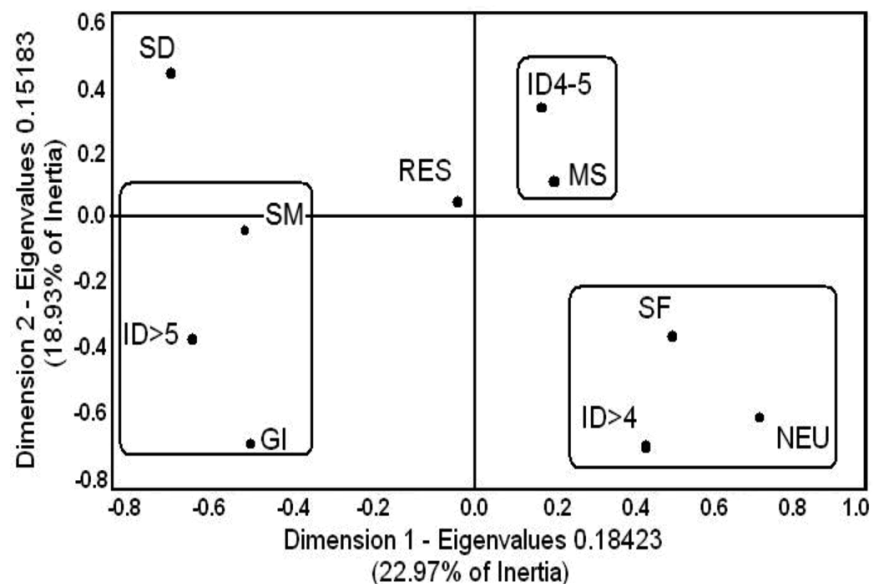

Fig.2. Perceptual map of correspondence relations between the variables gender (SM, SF); age group (ID<4, ID4-5, ID $>5$ ) and cause of death (MS, GI, SD, NEU, RES); during the 4-year period 2005, 2006, 2007 and 2008.

\section{DISCUSSION}

The 452 horses evaluated during the seven years period, corresponded to a mean of a little less than 64 animals necropsied per year. There were more males than females in the observed population. Considering the data analysis, there is largest number of deaths in males compared to females. This result should be observed with parsimony, considering that we can not use it as an indicator of population, based on specific characteristics of the population. Methodological differences restrict the comparisons of our results with those from the surveillance systems and monitoring of the official veterinary service of the United Kingdom (DEFRA) and the U.S. (APHIS), as well as with the results published by Stover and Murray (2008). Additionally, another limitation of our study is that we haven't had full access to the hospital medical records, which prevented the comparison of the data evaluated with the total number of animals treated in the same period. Nevertheless, this limitation can serve as warnings to the veterinary institutions have a greater control population of patients, through records and building databases. If implemented, this could be used as a basis for comparison in future studies.

Observing only a numerical interface, Stover and Murray (2008) recorded from 1990 to 2006 a total of 4000 horses necropsied (250 per year) and the Epidemiologic
Survey of Great Britain (DEFRA/AHT/BEVA 2008) during the years of 2004 to 2008 reported a total of 1106 horses necropsied (221 per year).

The ODVH is an institution that does not have a formally instituted postmortem program, isn't connected with pathology institutes and does not receive animals from other horse racing tracks. This characteristic is specificity in the analysis of deaths among Thoroughbred horses in this institution, confirming that this research does not represent the entire population of this breed.

The relationship between deaths and categories of organ systems involved found in this study are similar, at least in part, to those found by Calkins (2009) who separated the organ systems responsible for deaths (233) and observed that $70 \%$ (164) was of musculoskeletal origin and $11 \%$ (26) related to the gastrointestinal system (Table 2).

Considering the predominance of deaths arising from the musculoskeletal system the records of the ODVH are similar to some of the literature (Stover and Murray, 2008; Calkins 2009) (Table 2). However, in disagreement with the data of the ODVH, the guide of British epidemiology (DEFRA/AHT/ BEVA 2008) and the United States Department of Agriculture (USDA-UPHIS 2007), demonstrated a higher number of deaths of gastrointestinal origin, 29\% (322) and 22\%, followed by those of musculoskeletal origin, $11 \%$ (123) and $21 \%$, respectively (Table 2). Such discordance is likely due to the breed heterogeneity of the population evaluated in the two studies (DEFRA/AHT/BEVA 2008 and USDA-APHIS 2007), while the population described in the present study is exclusively thoroughbred horses whose intense athletic activity leads to lesions, preferentially musculoskeletal.

The age groups of horses that succumbed in ODVH demonstrated a greater percentage of animals with ages between four and five years, in contrast to the findings of Stover and Murray (2008) and Calkins (2009) who revealed a greater number of deaths among animals younger than four years old (Table 3 ). The study conducted by the USDA-UPHIS (2007), despite being important, cannot be cited because a very broad age scale was utilized (30 days to 5 months, 6 months to 4 years, 5 to 20 years, and older than 20 years) (Table 3 ).

In examining the perceptual map of the 3-year period (2002, 2003 and 2004), the strong relations exist between males older than five years of age and deaths of unknown origin are difficult to clearly interpret, due to the undetermined character of the genesis of these deaths. However, the direct correspondence with gender and age group serves as a starting point from the steering of future more detailed searches (Fig.1).

In the 3-year period (2002, 2003 and 2004, Fig.1), the correspondence, albeit moderate, of the horses of ages greater than five years and deaths involving the gastrointestinal system comes from the management to which these animals are submitted, independent of athletic routine. Only two large meals every $24 \mathrm{~h}$, feeding based on substantial quantities of concentrate rich in volatile carbohydrates and intensive fattening regimen, are key consequential issues of imbalance of gastrointestinal homeostasis (Nadeau et al., 2000). Nonetheless, in the 4-year period studied 
Table 2. Comparison of general mortality rate per major group of determined causes, between Hospital Veterinário Octavio Dupont (ODVH), Washington Horse Racing Commission (Calkins 2009), California Postmortem Program (Stover and Murray 2008) and guide of the Horse Epidemiologic Survey of Great Britain (DEFRA/AHT/BEVA 2008)

\begin{tabular}{|c|c|c|c|c|c|}
\hline $\begin{array}{l}\text { System in cause of death } \\
\text { (necroscopy report) }\end{array}$ & $\begin{array}{c}\text { ODVH } \\
2002-2008\end{array}$ & $\begin{array}{l}\text { Calkins 2009a } \\
\text { (2001-2007) }\end{array}$ & $\begin{array}{c}\text { Stover and } \\
\text { Murray 2008 } \\
(1991-2007)\end{array}$ & $\begin{array}{l}\text { DEFRA/AHT/BEVA } \\
(2004-2008)^{c}\end{array}$ & $\begin{array}{l}\text { USDA-APHIS 2007 } \\
(1998 / 2005)\end{array}$ \\
\hline Musculoskeletal (MS) & $53 \%$ & $70 \%$ & $79 \%$ & $11 \%$ & $21 \%$ \\
\hline Gastrointestinal (GI) & $21 \%$ & $11 \%$ & $6 \%$ & $29 \%$ & $22 \%$ \\
\hline Sudden death (SD) & $12 \%$ & $2 \%$ & $5 \%$ & $7 \%$ & $7 \%$ \\
\hline Respiratory (RES) & $6 \%$ & $9 \%$ & $6 \%$ & $6 \%$ & $3 \%$ \\
\hline Neurologic (NEU) & $8 \%$ & $3 \%$ & $2 \%$ & $4 \%$ & $2 \%$ \\
\hline Total animals evaluated & 452 & 233 & 4000 & 1106 & $\mathrm{NR}^{\mathrm{e}}$ \\
\hline \multicolumn{6}{|c|}{$\begin{array}{l}\text { a Were excluded deaths of cardiovascular origin, } n=9(4 \%) \text {. } \\
\text { b Were excluded deaths of cardiovascular, } n=40(1 \%) \text {, and cutaneous, } n=40(1 \%) \text {, origin. } \\
\text { c Were excluded deaths of reproductive, } n=338(31 \%) \text {, cardiac, } n=24(2 \%) \text {, and neoplastic, } n=55(5 \%) \text {, origin. } \\
\text { d Were excluded deaths of neoplastic }(3 \%) \text {, cardiac }(2 \%) \text {, reproductive }(3 \%) \text {, and old age }(30 \%) \text { origin, and } \\
\text { other causes }(7 \%) \text {. } \\
\text { e Not indicated by author. }\end{array}$} \\
\hline
\end{tabular}

Table 3. Comparison between the numeric and percentage relation between age groups of horse deaths in Hospital Veterinario Octavio Dupont (ODVH 2002-2008), Stover and Murray (2008) and Calkins 2009

\begin{tabular}{lccc}
\hline & $\begin{array}{c}\text { ODVH }^{*} \\
(2002-2008)\end{array}$ & $\begin{array}{c}\text { Stover and Murray (2008) } \\
1991-2007\end{array}$ & $\begin{array}{c}\text { (Calkins 2009) }^{\dagger} \\
2001-2008\end{array}$ \\
\hline ID $<4$ & $163(36 \%)$ & $1960(49 \%)$ & $140(60 \%)$ \\
ID4-5 & $182(40 \%)$ & $1320(33 \%)$ & $62(26 \%)$ \\
ID $>5$ & $107(24 \%)$ & $120(3 \%)$ & $31(13 \%)$ \\
${ }^{*} \mathrm{n}=452 ;^{\ddagger} \mathrm{n}=4000 ;{ }^{\dagger} \mathrm{n}=233$. & \\
${ }^{*} 600$ absent animals $(15 \%)$ corresponds to animals of breeds whose ages \\
were not described by the authors.
\end{tabular}

(2005, 2006, 2007 and 2008, Fig.2), there was an intensification of the correspondences between gastrointestinal deaths and horses older than five years old, making it clear the importance of these variables.

The correspondence between musculoskeletal deaths and animals belonging to the age group between four and five years is equal in the first 3-year period and second 4-year period evaluated (Fig.1 and 2). Such fact is almost exclusively explained by the fact of being a period of greater intensification of athletic activity exerted by these horses. A more intense regimen of presentations consequently causes a greater accumulation of distances between training and performance tests which expose them more to risks inherent to the sport.

The correspondence between females younger than four years dying from respiratory system and neurologic ailments, contrasts the findings of Baker \& Johnson (1999) who in their study of deaths of respiratory origin, indicated females as accounting for less than half of deaths. In the same study, the animals younger than four years (without reference to sex) represented more than $60 \%$ (59/101) of the deaths. The correspondence between young females and neurologic deaths should be interpreted with caution, mainly due to the strong correspondence relation demonstrated at the evaluation of the 4-year period, serving thus as a reference for later studies.

Multifactorial issues require multivariate interpretations. It is important to emphasize that the multivariate correlation is intended only to explore a set of categorical measures that may be affected by multiple factors, with the least possible loss of information. Based on this premise, it was aimed to delineate a line of investigation the accessibility and multivariate epidemiologic interpretation of the correspondences on horse deaths. It is understood that epidemiologic surveys of this nature are only capable of solidifying objectives based on availability of and correspondence between the greatest amounts of information possible. This goal can only be met with the construction of reliable databases of deaths, and as a reflection of the success of international entities, the confluence of multidisciplinary actions among various medico-veterinary sectors both public and private.

\section{REFERENCES}

Baker C. K. \& Johnson B. 1999. Review of postmortem findings in cases of pneumonia in California racehorses. Proc. American Association of Equine Practitioners, Albuquerque, New Mexico, p.319-321.

Calkins S. 2005. Equine Health and Safety Report 2001-2004, Post Mortem Report. Washington Horse Racing Commission (WHRC). <http://www. whrc.wa.gov> Accessed Jul. 13, 2011.

Calkins S. 2009. Equine Health and Safety Report 2008. Washington Horse Racing Commission (WHRC). <http//www.whrc.wa.gov> Accessed Jul. 13, 2011.

DEFRA/AHT/BEVA 2008. Equine Quarterly Disease Surveillance Report. January-March 2008. Vol.4, no.1. <http//www.aht.org.uk.pdf> Accessed Dec. 15, 2008.

Fio L. 2002. Looking for a cause of injures: Racehorse Postmortem Program. <http//www.ctba.com.pdf> Accessed Dec. 13, 2008.

Hair J.F., Anderson R.E., Tathan R.L. \& Black W.C. 2009. Análise multivariada de dados. $6^{\mathrm{a}}$ ed. Bookman, Porto Alegre, RS. 688p.

Jhonson G.M., Eastement J.K., Wood J.L.N. \& Taylor P.M. 2002. The confidential enquiry into perioperative equine fatalities (CEPEF): Mortality results of Phases 1 and 2. Vet. Anaesth. Analg. 29:159-170.

Manly B.F.J. 2008. Métodos Estatísticos Multivariados: uma introdução. 3ạ ed. Bookman, Porto Alegre, RS. 229p.

Nadeau J.A., Andrews F.M. \& Mathew A.G. 2000. Evaluation of diet as a cause of gastric ulcers in horses. Am. J. Vet. Res. 61:784-790.

NAHMS 2007. Department of Agriculture's National Animal Health Monitoring Systems. <http//www.nahms.aphis.usda.gov.pdf> Accessed Dec. 13, 2008.

Stover M.S \& Murray A. 2008. The California Postmortem Program: Leading the way. Vet. Clin. North Am., Equine Pract. 24:21-36.

USDA:APHIS 2007. Trends in Equine Mortality, 1998-2005. <http//www. aphis.usda.gov/vs/ceah/ncahs> Accessed Dec. 15, 2008. 